\title{
BOUNDING THE SÁNDOR-YANG MEANS FOR THE COMBINATIONS OF CONTRAHARMONIC AND ARITHMETIC MEANS
}

\section{Wei-Mao Qian, Hui-Zuo Xu, Zai-Yin He and Yu-Ming Chu*}

Abstract. In the article, we prove that $t_{1}=1 / 2+\sqrt{2^{1 /(2 p)} e^{(\pi-4) /(4 p)}-1} / 2, t_{2}=1 / 2+\sqrt{6 p} /(12 p)$, $t_{3}=1 / 2+\sqrt{(1+\sqrt{2})^{\sqrt{2} / p} / e^{1 / p}-1} / 2$ and $t_{4}=1 / 2+\sqrt{3 p} /(6 p)$ are the best possible parameters on the interval $[1 / 2,1]$ such that the double inequalities

$$
\begin{aligned}
C^{p}\left[t_{1} u+\right. & \left.\left(1-t_{1}\right) v, t_{1} v+\left(1-t_{1}\right) u\right] A^{1-p}(u, v)<Q(u, v) e^{\frac{A(u, v)}{\mathscr{T}(u, v)}-1} \\
& <C^{p}\left[t_{2} u+\left(1-t_{2}\right) v, t_{2} v+\left(1-t_{2}\right) u\right] A^{1-p}(u, v), \\
C^{p}\left[t_{3} u+\right. & \left.\left(1-t_{3}\right) v, t_{3} v+\left(1-t_{3}\right) u\right] A^{1-p}(u, v)<A(u, v) e^{\frac{Q(u, v)}{\mathscr{S}(u, v)}-1} \\
& <C^{p}\left[t_{4} u+\left(1-t_{4}\right) v, t_{4} v+\left(1-t_{4}\right) u\right] A^{1-p}(u, v)
\end{aligned}
$$

hold for all $u, v>0$ with $u \neq v$ and $p \in[1 / 2, \infty)$, where $A(u, v)=(u+v) / 2, Q(u, v)=$ $\sqrt{\left(u^{2}+v^{2}\right) / 2}, C(u, v)=\left(u^{2}+v^{2}\right) /(u+v), \mathscr{T}(u, v)=(u-v) /[2 \arctan ((u-v) /(u+v))]$ and $\mathscr{N} \mathscr{S}(u, v)=(u-v) /\left[2 \sinh ^{-1}((u-v) /(u+v))\right]$ are respectively the arithmetic, quadratic, contraharmonic, Seiffert and Neuman-Sándor means of $u$ and $v$, and $\sinh ^{-1}(x)=\log \left(x+\sqrt{x^{2}+1}\right)$ is the inverse hyperbolic sine function.

Mathematics subject classification (2020): 26E60.

Keywords and phrases: Arithmetic mean, quadratic mean, Seiffert mean, Neuman-Sándor mean, contraharmonic mean, Schwab-Borchardt mean.

\section{REFERENCES}

[1] M. Adil Khan, S.-H. Wu, H. Ullah, And Y.-M. Chu, Discrete majorization type inequalities for convex functions on rectangles, J. Inequal. Appl., 2019, 2019, Article 16, 18 pages.

[2] G. D. Anderson, M. K. Vamanamurthy and M. K. Vuorinen, Conformal Invariants, Inequalities, and Quasiconformal Maps, John Wiley \& Sons, New York, 1997.

[3] P. S. Bullen, Handbook of Means and Their Inequalities, Kluwer Academic Publishers Group, Dordrecht, 2003.

[4] Z.-W. Cai, J.-H. HuAng, And L.-H. HuAng, Periodic orbit analysis for the delayed Filippov system, Proc. Amer. Math. Soc., 2018, 146 (11), 4667-4682.

[5] B. C. CARlson, Algorithms involving arithmetic and geometric means, Amer. Math. Monthly, 1971, 78, 496-505.

[6] H.-H. Chu, W.-M. Qian, Y.-M. Chu, AND Y.-Q. Song, Optimal bounds for a Toader-type mean in terms of one-parameter quadratic and contraharmonic means, J. Nonlinear Sci. Appl., 2016, 9 (5), 3424-3432.

[7] Y.-M. Chu AND S.-W. Hou, Sharp bounds for Seiffert mean in terms of contraharmonic mean, Abstr. Appl. Anal., 2012, 2012, Article ID 425175, 6 pages.

[8] Y.-M. Chu AND B.-Y. Long, Best possible inequalities between generalized logarithmic mean and classical means, Abstr. Appl. Anal., 2010, 2010, Article ID 303286, 13 pages.

[9] Y.-M. CHU AND B.-Y. LonG, Sharp inequalities between means, Math. Inequal. Appl., 2011, 14 (3), $647-655$. 
[10] Y.-M. CHU, Y.-F. QIU, AND M.-K. WANG, Sharp power mean bounds for the combination of Seiffert and geometric means, Abstr. Appl. Anal., 2010, 2010, Article ID 108920, 12 pages.

[11] Y.-M. ChU, Y.-F. QIU, AND M.-K. WANG, Hölder mean inequalities for the complete elliptic integrals, Integral Transforms Spec. Funct., 2012, 23 (7), 521-527.

[12] Y.-M. CHU AND M.-K. WANG, Inequalities between arithmetic-geometric, Gini, and Toader means, Abstr. Appl. Anal., 2012, 2012, Article ID 830585, 11 pages.

[13] Y.-M. CHU AND M.-K. WANG, Optimal Lehmer mean bounds for the Toader mean, Results Math., 2012, 61 (3-4), 223-229.

[14] Y.-M. CHU, M.-K. WANG, Y.-P. JANG, S.-L. QIU, Concavity of the complete elliptic integrals of the second kind with respect to Hölder means, J. Math. Anal. Appl., 2012, 395 (2), 637-642.

[15] Y.-M. CHU, M.-K. WANG, AND S.-L. QIU, Optimal combinations bounds of root-square and arithmetic means for Toader mean, Proc. Indian Acad. Sci. Math. Sci., 2012, 122 (1), 41-51.

[16] Y.-M. CHU, M.-K. WANG, AND Z.-K. WANG, Best possible inequalities among harmonic, geometric, logarithmic and Seiffert means, Math. Inequal. Appl., 2012, 15 (2), 415-422.

[17] Y.-M. CHU AND W.-F. XIA, Two optimal double inequalities between power mean and logarithmic mean, Comput. Math. Appl., 2010, 60 (1), 83-89.

[18] Y.-M. ChU AND T.-H. ZhaO, Concavity of the error function with respect to Hölder means, Math. Inequal. Appl., 2016, 19 (2), 589-595.

[19] Y.-M. ChU, C. ZonG, AND G.-D. WANG, Optimal convex combination bounds of Seiffert and geometric means for the arithmetic mean, J. Math. Inequal., 2011, 5 (3), 429-434.

[20] Z.-F. DAI, Comments on a new class of nonlinear conjugate gradient coefficients with global convergence properties, Appl. Math. Comput., 2016, 276, 297-300.

[21] L. DUAN, X.-W. FANG, AND C.-X. HUANG, Global exponential convergence in a delayed almost periodic Nicholson's blowflies model with discontinuous harvesting, Math. Methods Appl. Sci., 2018, 41 (5), 1954-1965.

[22] L. Duan, L.-H. Huang, Z.-Y. Guo, And X.-W. FAng, Periodic attractor for reaction-diffusion high-order Hopfield neural networks with time-varying delays, Comput. Math. Appl., 2017, 73 (2), 233-245.

[23] H.-J. HU AND L.-Z. LIU, Weighted inequalities for a general commutator associated to a singular integral operator satisfying a variant of Hörmander's condition, Math. Notes, 2017, 101 (5-6), 830840.

[24] C.-X. Huang, S. Guo, AND L.-Z. Liu, Boundedness on Morrey space for Toeplitz type operator associated to singular integral operator with variable Calderón-Zygmund kernel, J. Math. Inequal., 2014, 8 (3), 453-464.

[25] C.-X. HUANG AND L.-Z. LiU, Sharp function inequalities and boundness for Toeplitz type operator related to general fractional singular integral operator, Publications De L Institut Math. (Beograd) (N. S.), 2012, 92 (106), 165-176.

[26] C.-X. HuANG AND L.-Z. LiU, Boundedness of multilinear singular integral operator with a nonsmooth kernel and mean oscillation, Quaest. Math., 2017, 40 (3), 295-312.

[27] C.-X. Huang, C.-L. Peng, X.-H. Chen, And F.-H. Wen, Dynamics analysis of a class of delayed economic model, Abstr. Appl. Anal., 2013, 2013, Article ID 962738, 12 pages.

[28] C.-X. Huang, Y.-C. QiaO, L.-H. Huang, ANd R.-P. Agarwal, Dynamical behaviors of a foodchain model with stage structure and time delays, Adv. Differences Equ., 2018, 2018, Article 186, 26 pages.

[29] Y.-X. Li, M. A. Ali, H. Budak, M. Abbas, And Y.-M. Chu, A new generalization of some quantum integral inequalities for quantum differentiable convex functions, Adv. Difference Equ., 2021, 2021, Article 225, 15 pages.

[30] Y.-X. Li, M. H. Alshbool, Y.-P. Lv, I. Khan, M. RiZa Khan, And A. IssaKhov, Heat and mass transfer in MHD Williamson nanofluid flow over an exponentially porous stretching surface, Case Stud. Therm. Eng., 2021, 26, Article ID 100975, 10 pages.

[31] Y.-X. Li, T. Muhammad, M. Bilal, M. Altaf Khan, A. Ahmadian, and B. A. Pansera, Fractional simulation for Darcy-Forchheimer hybrid nanoliquid flow with partial slip over a spinning disk, Alex. Eng. J., 2021, 60, 4787-4796.

[32] Y.-X. Li, A. Rauf, M. Naeem, M. A. Binyamin, And A. Aslam, Valency-based topological properties of linear hexagonal chain and hammer-like benzenoid, Complexity, 2021, 2021, Article ID 9939469,16 pages. 
[33] Y.-X. Li, F. Shah, M. Ijaz Khan, R. Chinram, Y. Elmasry, and T.-C. Sun, Dynamics of Cattaneo-Christov double diffusion (CCDD) and arrhenius activation law on mixed convective flow towards a stretched Riga device, Chaos Solitons Fractals, 2021, 148, Article ID 111010, 5 pages.

[34] E. Neuman And J. SÁndor, On the Schwab-Borchardt mean, Math. Pannon., 2003, 14 (2), $253-$ 266.

[35] E. Neuman And J. SÁndor, On the Schwab-Borchardt mean II, Math. Pannon., 2006, 17 (1), 49 59.

[36] W.-M. QIAN AND Y.-M. CHU, Sharp bounds for a special quasi-arithmetic mean in terms of arithmetic and geometric means with two parameters, J. Inequal. Appl., 2017, 2017, Article 274, 10 pages.

[37] W.-M. QIAN, H.-Z. XU, AND Y.-M. CHU, Improvements of bounds for the Sándor-Yang means, J. Inequal. Appl., 2019, 2019, Article 73, 8 pages.

[38] W.-M. QIAN, X.-H. ZHANG, AND Y.-M. CHU, Sharp bounds for the Toader-Qi mean in terms of harmonic and geometric means, J. Math. Inequal., 2017, 11 (1), 121-127.

[39] S.-L. QIU, X.-Y. MA, AND Y.-M. CHU, Sharp Landen transformation inequalities for hypergeometric functions, with applications, J. Math. Anal. Appl., 2019, 474 (2), 1306-1337.

[40] J. SÁnDOR, Two sharp inequalities for trigonometric and hyperbolic functions, Math. Inequal. Appl., 2012, 15 (2), 409-413.

[41] Y.-X. TAN, C.-X. HuAng, B. Sun, And T. WANG, Dynamics of a class of delayed reactiondiffusion systems with Neuman boundary condition, J. Math. Anal. Appl., 2018, 458 (2), 1115-1130.

[42] W.-S. TANG AND Y.-J. Sun, Construction of Runge-Kutta type methods for solving ordinary differential equations, Appl. Math. Comput., 2014, 234, 179-191.

[43] J.-F. WANG, X.-Y. CHEN, AND L.-H. HuANG, The number and stability of limit cycles for plannar piecewise linear systems of mode-saddle type, J. Math. Anal. Appl., 2019, 469 (1), 405-427.

[44] J.-L. WANG, W.-M. QIAn, Z.-Y. HE, AND Y.-M. CHU, On approximating the Toader mean by other bivariate means, J. Funct. Spaces, 2019, 2019, Article ID 6082413, 7 pages.

[45] M.-K. WAng, Y.-M. CHU, Aymptotical bounds for complete elliptic integrals of the second kind, J. Math. Anal. Appl., 2013, 402 (1), 119-126.

[46] M.-K. WAng, Y.-M. CHU, Y.-F. QIU, AND S.-L. QIU, An optimal power mean inequality for the complete elliptic integrals, Appl. Math. Lett., 2011, 24 (6), 887-890.

[47] M.-K. WANG, Y.-M. CHU, AND W. ZHANG, Monotonicity and inequalities involving zero-balanced hypergeometric function, Math. Inequal. Appl., 2019, 22 (2), 601-617.

[48] M.-K. WANG, Y.-F. QIU, AND Y.-M. CHU, Sharp bounds for Seiffert means in terms of Lehmer means, J. Math. Inequal., 2010, 4 (4), 581-586.

[49] M.-K. WANG, Z.-K. WANG, AND Y.-M. CHU, An optimal double inequality between geometric and identric means, Appl. Math. Lett., 2012, 25 (3), 471-475.

[50] Y.-Y. YANG, W.-M. QIAN, ADN Y.-M. CHU, Refinements of bounds for Neuman means with applications, J. Nonlinear Sci. Appl., 2016, 9 (4), 1529-1540.

[51] Z.-H. YANG, Three families of two-parameter means constructed by trigonometric functions, J. Inequal. Appl., 2013, 2013, Article 541, 27 pages.

[52] Z.-H. YANG, Y.-M. CHU, AND W. ZHANG, High accuracy asymptotic bounds for the complete elliptic integral of the second kind, Appl. Math. Comput., 2019, 348, 552-564.

[53] Z.-H. YAnG, W.-M. QiAn, AND Y.-M. CHU, Monotoncity properties and bounds involving the complete elliptic integrals of the first kind, Math. Inequal. Appl., 2018, 21 (4), 1185-1189.

[54] Z.-H. YANG, W.-M. QIAN, Y.-M. CHU, AND W. ZHANG, Monotonicity rule for the quotient of two functions and its application, J. Inequal. Appl., 2017, 2017, Article 106, 13 pages.

[55] Z.-H. YANG, W.-M. QIAN, Y.-M. CHU, AND W. ZHANG, On rational bounds for the gamma function, J. Inequal. Appl., 2017, 2017, Article 210, 17 pages.

[56] Y. ZHANG, On products of consecutive arithmetic progressions II, Acta Math. Hungra., 2018, 156 (1), 240-254.

[57] T.-H. ZhaO, W.-M. Qian And Y.-Q. Song, Optimal bounds for two Sándor-type means in terms of power means, J. Inequal. Appl., 2016, 2016, Article 64, 10 pages.

[58] T.-H. ZHAO, M.-K. WANG, AND Y.-M. CHU, Quadratic transformation inequalities for Gaussian hypergeometric function, J. Inequal. Appl., 2018, 2018, Article 251, 15 pages.

[59] T.-H. ZhaO, B.-C. ZHOU, M.-K. WANG, AND Y.-M. CHU, On approximating the quasi-arithmetic mean, J. Inequal. Appl., 2019, 2019, Article 42, 12 pages. 
[60] K.-X. Zhu, Y.-Q. XIE, AND F. ZHOU, Pullback attractors for a damped semilinear wave equation with delays, Acta Math. Sin., 2018, 34 (7), 1131-1150. 